\title{
Soil physical environment as affected by double zero tillage in rice-wheat cropping system of north-west India
}

RAJAN BHATT AND S.S. KUKAL

Received : 24.03.2015; Accepted : 29.05.2015

\author{
MEMBERS OF RESEARCH FORUM: \\ Corresponding author : \\ RAJAN BHATT, Department of Soil \\ Science, Punjab Agricultural \\ University, LUDHIANA (PUNJAB) \\ INDIA
}

\begin{abstract}
Summary
Highly productive rice (Oryza sativa L.) and wheat (Triticum aestivum L.) cropping systems are crucial for millions of rural and urbans in the Indo-Gangetic Plains (IGP) of south Asia. This intensive RWCS resulted in declining under groundwater table and degrading soil health. A number of resource conservation technologies are being propagated in the region to uplift declining water productivity and soil health. Among different propagated resource conservation technologies-double zero tillage (ZT-wheat) in both crops found to be adopted in the region at a large scale which lessens cost of cultivation with no-field preparation and no-pre-sowing irrigation factor. Further, as wheat sown in loose and anchored rice straw thus, emit burning of rice residues and finally, reduces air pollution and improves "blank gold" status (Soil organic carbon). Zero tillage supposed to improve the declining soil physical properties; crop and water productivity thought visible effects appeared after 4-5 years of adoption. The treatment included two tillage levels viz., conventional and zero tillage and three rice tillage viz., puddle, conventionally and zero tilled with two establishment methods viz., direct seeded rice (DSR) and mechanically transplanted rice (MTR). Objective of the present study was to delineate the effect of double zero tillage from 2012-2014 on the soil physical environment and findings suggests that double tillage was not able to significantly effect of the physical properties of the soil as adaptation of CA based component technologies evolved over the time. Thus, best benefits of double zero tillage might be significant after 3-5 years of continuous adoption of the double zero tillage which further needs to be tested under different agro-climatic conditions under texturally divergent soils.
\end{abstract}

Key words : Double zero tillage, Rice-wheat cropping system, Physical environment, Northwest India

How to cite this article : Bhatt, Rajan and Kukal, S.S. (2015). Soil physical environment as affected by double zero tillage in rice-wheat cropping system of north-west India. Asian J. Soil Sci., 10(1) : 166-172. 